\title{
A bioeroding foraminifer, Hyrrokkin sarcophaga, on deepwater corals from the South China Sea
}
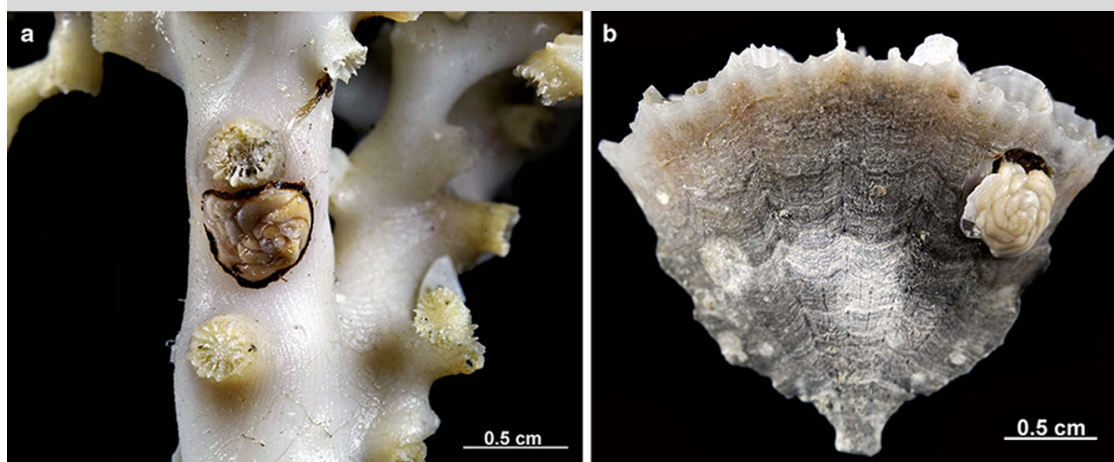

Foraminifera are widely distributed in the world's oceans. Approximately 23 species have been reported to bore into the hard substrate of hosts mainly from shallow-water coral reefs, but only few species from cold-water coral ecosystems are known to date (Beuck et al. 2008). Hyrrokkin sarcophaga is a commensal/parasitic foraminifer with large body size (tests up to $7 \mathrm{~mm}$ in diameter) that infests hexacorals (Lophelia pertusa, Madrepora oculata, Caryophyllia sarsiae) and an octocoral (Primnoa resedaeformis) in aphotic environments (Cedhagen 1994). Its biogeographic distribution has previously been reported as within the 200 - to 500 -m-depth
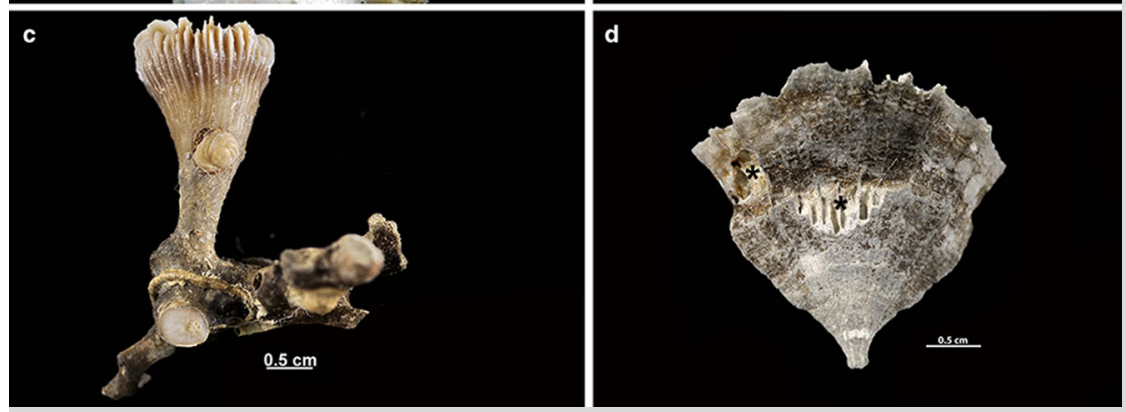

Fig. 1 a Live Madrepora oculata colonized by Hyrrokkin sarcophaga; b a $H$. sarcophaga foraminifer on Flabellum japonicum forming a depression; c Caryophyllia diomedeae infected by $H$. sarcophaga located at the polyp's basal edge; $\mathbf{d}$ attachment scars (asterisk) of $H$. sarcophaga on $F$. japonicum. All specimens were preserved in $70 \%$ ethanol interval along the North Atlantic continental margin from polar to subtropical where water temperature is from 5 to $11^{\circ} \mathrm{C}$ (Freiwald and Schönfeld 1996; Beuck et al. 2008). From December 2013 to August 2015, 15 individuals of $H$. sarcophaga were discovered on three deepwater coral species collected with beam trawl at 339-552 m depth in the South China Sea (Electronic Supplementary Material). The host corals included Madrepora oculata $(1$ of 3 specimens examined; Fig. 1a), Flabellum japonicum (13 of 210 specimens examined; Fig. 1b), and Caryophyllia diomedeae ( 1 of 1 specimen collected; Fig. 1c). The test of $H$. sarcophaga attached to the host coral skeleton was marginally surrounded by brown organic residue that induced a depression on the skeleton of host coral. The borings produced by this large foraminifer are characterized by a shallow groove of $0.55 \pm 0.04 \mathrm{~mm}$ (mean $\pm \mathrm{SD}, n=11$ ) in diameter (Fig. $1 \mathrm{~d}$ ), from which several whip-shaped extensions protrude vertically into the substrate of hosts and act as an anchor to enhance the attachment (Beuck et al. 2008; Cedhagen 1994). This is the first report of the occurrence of $H$. sarcophaga in the Pacific. It extends our knowledge of the global distribution of $H$. sarcophag $a$ as well as its ecological affinity and host preference.

Acknowledgments We are especially grateful to Dr. Stephen Cairns at the National Museum of Natural History for his assistance in the identification of deepwater corals. This study was sponsored by the Ministry of Science and Technology, Taiwan, R. O. C. (MOST104-2621-B-002-001).

\section{References}

Beuck L, López Correa M, Freiwald A (2008) Biogeographical distribution of Hyrrokkin (Rosalinidae, Foraminifera) and its host-specific morphological and textural trace variability. In: Wisshak M, Tapanila L (eds) Current developments in bioerosion. Springer, Heidelberg, pp 329-360

Cedhagen T (1994) Taxonomy and biology of Hyrrokkin sarcophaga gen. et sp. n.: a parasitic foraminiferan (Rosalinidae). Sarsia 79:65-82

Freiwald A, Schönfeld J (1996) Substrate pitting and boring pattern of Hyrrokkin sarcophaga Cedhagen, 1994 (Foraminifera) in a modern deep-water coral reef mound. Mar Micropaleontol 28:199-207

Electronic supplementary material The online version of this article (doi:10.1007/s00338-016-1447-7) contains supplementary material, which is available to authorized users.

\section{Y.-R. Cheng · C.-F. Dai $(\bowtie)$}

Institute of Oceanography, National Taiwan University, No. 1 Roosevelt Road, Section 4, Taipei 106, Taiwan

e-mail: corallab@ntu.edu.tw 